\title{
Face mask effects during COVID-19: perspectives of managers, practitioners and customers in the hotel industry
}

\author{
Anthony Kong, Jae-Eun Oh and Terry Lam \\ School of Design, The Hong Kong Polytechnic University, Kowloon, China
}

Received 16 July 2020 Revised 15 November 2020 22 March 2021

Accepted 22 March 2021

\begin{abstract}
Purpose - The novel coronavirus (COVID-19) has completely changed the landscape of the hospitality industry. The World Health Organization does not officially recommend wearing face masks in the workplace. Wearing face masks is controversial worldwide, however it has been widely adopted in Hong Kong society. Hospitality practitioners have worn face masks to work and serve customers for almost a year long, matching the duration of the COVID-19 pandemic. This paper proposes a conceptual model of face mask effects and also discusses and evaluates the effects of wearing face masks during the pandemic.

Design/methodology/approach - A convenience sampling method is employed to investigate hospitality operators using in-depth and focus group interviews with managers, front-line staff and customers.

Findings - The perspectives of both hospitality practitioners and customers are included in this study. The concepts of (1) invisible care, (2) sense of safety and (3) service trust have been introduced in this study. These provide valuable insights for the service industry when facing a large-scale health crisis, now and in the future. Research limitations/implications - This paper analyzes interview data collected from 35 respondents 14 managers, 6 practitioners and 15 customers - in order to understand the critical effects of wearing face masks during the pandemic and the perspectives of both hospitality practitioners and customers.

Practical implications - For the hospitality industry, wearing face mask in service has already become a "new normal", face mask effects might create an impact on service design, service delivery and service quality. Originality/value - The findings show that wearing face masks turns hygiene and safety into a form of invisible care in the Asian hospitality industry. Practitioners' perspective regarding the necessity of a smile is less important to Asian customers, showing a discrepancy between the two parties. Customers do not believe that service quality has dropped due to the wearing of masks, but that the level of hygiene has risen. Unlike customers, practitioners are more concerned about not providing good quality service. However, the interview data show that respondents generally agree that mask wearing is a gesture and symbol for the hospitality industry to make tangible a new form of caring, professionalism, safety concern and communication.
\end{abstract}

Keywords COVID-19, Face mask effect, Hotel industry, Service

Paper type Research paper

\section{Introduction}

With the outbreak of the novel coronavirus (COVID-19), the tourism and hospitality industry has been one of the hardest-hit sectors internationally and locally due to the lockdown of public areas and social distancing (Jones and Comfort, 2020). After the World Health Organization (WHO) declared COVID-19 a pandemic on March 11, 2020 (WHO, 2020), widespread travel bans and restrictions on socializing were implemented worldwide. Various countries implemented 6-foot (1.5-m) social distancing and temperature scanning at the entrance to public spaces. The declaration had a severe impact on business operations in the

(C) Anthony Kong, Jae-Eun Oh and Terry Lam. Published in International Hospitality Review. Published by Emerald Publishing Limited. This article is published under the Creative Commons Attribution (CC BY 4.0) licence. Anyone may reproduce, distribute, translate and create derivative works of this article (for both commercial and non-commercial purposes), subject to full attribution to the original publication and authors. The full terms of this licence may be seen at http://creativecommons.org/ licences/by/4.0/legalcode

Face masks effects in the hotel industry 
IHR

35,2

196

tourism and hospitality industry, resulting in canceled events (i.e. conferences, music concerts, film festivals, art shows, the Olympics and other sports events), closed attractions (i.e. theme parks, cinemas, restaurants, bars and clubs) and the enforcement of 14-day quarantines. This affected many business segments negatively (Gossling et al., 2020) and had adverse consequences for the tourism and hospitality industry.

As people were not able to travel, hotel-, airline- and service-related businesses were hit particularly hard, especially in Hong Kong, where various small businesses rely heavily on the influx of tourists and tourism income (Tse et al., 2017). The real estate and investment management company Colliers International had a negative outlook for the tourism industry in Hong Kong and did not see it recovering fully in the nearest future (Tang and Wong, 2020). Many hotels offered lower rates than before, and experts predicted that prices will remain low (Hong Kong Business, 2020) for the rest of 2020. From January to april 2020, the hotel room occupancy rate stood at $39 \%$, compared with $91 \%$ in 2019 , a $52 \%$ decline (Hong Kong Tourism Board, 2020). Facing this adversity, hotels offered, as a survival tactic, "quarantine services" for customers who wanted to stay away from family members for their safety. In this context, tourism and hospitality industry personnel have been exposed to the virus by potentially infected hotel customers, restaurant customers and others (RTHK, 2020). Fortunately, Hong Kong is one of the few cities where citizens actively started wearing surgical masks at the very early stage of the outbreak. Chien and Law (2003) addressed the issue of Severe Acute Respiratory Syndrome (SARS) crisis management in risk identification, assessment and alleviation. Kim et al. (2005) revealed the cost operating management and staff training to tackle the SARS outbreak. From the health and the tourism perspective, Centre of Health Protection, Department of Health, the government of Hong Kong Special Administrative Region introduced guidelines for the maintenance of hygiene within hotel premises (Hung et al, 2018). The previous SARS epidemic experience in 2003 equipped Hong Kong in a more efficient way than other cities. Hong Kong took quick action to prevent the disease from spreading by making the wearing of masks essential in the public area, and citizens adjusted their behavior, taking precautions even before the government mandated them (Lee, 2020). Initially, the WHO did not advise the public to wear face masks all the time and did not urge them to be worn in workplaces although they later reversed their stance on wearing face masks in public (Lau, 2020). However, the Hong Kong Department of Health (Centre for Health Prevention, 2020a) announced guidelines regarding the wearing of face masks as follows:

Surgical masks can prevent transmission of respiratory viruses from ill persons. It is essential for persons who are symptomatic (even if having mild symptoms) to wear a surgical mask.

Wear a surgical mask when taking public transport or staying in crowded places. It is important to wear a mask properly, including hand hygiene before wearing and after removing a mask.

Hong Kong residents strictly followed the guidelines and started social distancing with extra cautiousness in public spaces. Due to these efforts, Hong Kong managed to keep the number of locally infected cases and the death rate low without having to implement a lockdown (Lee, 2020).

The wearing of face masks varies across different regions and cultures. Citizens of most Asian countries choose to wear masks (Feng et al., 2020) to reduce disease transmission and to symbolize solidarity and cooperative efforts in Asia. In the West, people have traditionally not been willing to wear face masks as a prevention method (Feng et al., 2020), but fears of the pandemic could temporarily reduce the resistance to masks (Zheng, 2020). With the East and West having different cultural perspectives, wearing surgical masks is a controversial practice (Feng et al., 2020), but it is widely adopted in Hong Kong society. Additionally, the Hong Kong government rolled out a set of health advice exclusively for the hotel industry 
(Centre for Health Protection, 2020b). According to this advice, every staff member must wear a mask when carrying out their respective jobs. As some hotels and businesses in the Hong Kong hospitality industry set the mask-wearing policy for both staff and customers, practitioners began to wear a face mask to work and serve customers since the outbreak of COVID-19. The gesture of hospitality professionals wearing masks has been presented as showing care for their customers and their safety (Severson, 2020). This new form of caring action can be developed as a new communication skill to demonstrate practitioners' professionalism toward customers.

Regarding the wearing of face masks, critical questions can therefore be posed: (1) What are the effects generated by wearing a surgical face mask? (2) How do practitioners serve customers while always keeping the surgical face mask on? (3) Does it affect the quality of service? (4) What are the difficulties that hospitality practitioners encounter? A convenience sampling method was employed to investigate the effect of hospitality operators wearing masks as a prominent tactic to display their caring attitude toward customers and identify the struggles and challenges that they encountered with in-depth and focus group interviews with managers, frontline staff and customers. Seven purposive interview questions were asked during face-to-face and focus group interviews. The study discusses the questions and evaluates the effects of wearing face masks during the pandemic. The perspectives of hospitality practitioners are included in the study, which provides valuable insights for the service industry when facing large-scale health crises.

\section{Literature review}

\subsection{Communication in hospitality}

The communication skills of frontline staff are one of the key indicators of hospitality business success (Nikolich and Sparks, 1995). Brownell (1992) posits that successful service is identical to efficient communication by hospitality practitioners, who must put in effort to maintain good relationships with their customers. Aside from verbal communication, hospitality industry practitioners are required to display well-trained nonverbal communication signs (Islam and Kirillova, 2020; Jung and Yoon, 2011; Sperber and Wilson, 1995) that are the attitude perceived by customers through facial expressions and gestures (Kueh and Bagul, 2013). The effects of hotel employees' nonverbal communication on the emotional responses of hotel customers are as powerful as those of verbal communication (Islam and Kirillova, 2020). Nonverbal communication is complex and associated with verbal communication development, which can cause both positive and negative emotions in customers (Knapp and Hall, 2006) through practitioners' behavior and intentions regarding service. These emotional responses can be evoked by diverse facial expressions, eye contact and body language, implying that emotional communication can happen subconsciously while interacting with others (Dimberg et al., 2000). It is crucial for both service providers and customers to be able to see facial expressions to prompt responses that help to settle any type of disagreement and improve the quality of service (Lemon and Verhoef, 2016). Zeithaml et al. (1996) also point out that the nonverbal demeanor contributes to perceptions of a more pleasing attitude and less anxiety about the future relationship. However, after the unexpected pandemic outbreak, hospitality industry practitioners began wearing face masks when serving their customers (Centre for Health Protection, 2020b) as one of the nonverbal communication methods to ensure safety that has become the new practice of hospitality and the new health code (Severson, 2020). Wearing masks requires much more effort from practitioners, according to one of our interviewees, as they are not able to show their smiles or other facial expressions, and in a similar vein, it is difficult for them to perceive what their customers need. In this regard, service providers need to be more flexible in terms of communicating with others when they wear face masks by
Face masks effects in the hotel industry 
IHR

35,2

198

adopting a good mixture of verbal and nonverbal communication skills, using the right vocal tone, pitch of voice and sound that clearly delivers the message (Islam and Kirillova, 2020).

\subsection{Emotional labor and mood}

In modern society, service has become the mainstay of production. We now need a workforce that is not focused on mechanical skills, but rather on serving people as the most important task. In the daily work of the modern labor force, interpersonal communication is the most important aspect, and interpersonal relationships have become a very important and valuable skill.

Echoing the observation regarding the service industry's labor needs, Spelman (1985) researched and conceptualized the idea of emotional labor. This is a job skill requirement in various types of jobs. According to Spelman (1985), emotional labor requires training and supervision of service to enable a practitioner to trigger a certain emotion, for example, gratitude, in a customer using face-to-face or voice-to-voice contact.

There are three main discourses concerning the study of emotional labor: the labor itself, the methods of display and the emotion that results from service. In the service industry, most practitioners are actors; to borrow Stanislavski's method acting theory, they perform deep acting (Chu and Murrmann, 2006; Spelman, 1985; Tucker et al., 2011; Wessel and Steiner, 2014) on their work stage. In terms of emotional labor, they need to have a transmutation of social life (Spelman, 1985), having a strong belief that they actually can present smiles from bottom of their hearts as if they truly are happy when they serve others.

They need to ensure that their emotional expressions are standardized as set by the corporate as a commercial product that represents and creates value for the company (Taheri et al., 2017). The public display of emotions is therefore part of the job of emotional labor; it is not only about what they do but also about how they do it. It is the commercialization of human feeling, but at the same time, this motive must be hidden. Corporate tends to use ideas of professional attitudes and turn it into a culture which promotes a "natural" feeling of acting.

In daily practice, emotional labor manages feelings by introducing certain "feeling rules." They link certain "emotional memories" from daily experience. For example, a flight attendant might think of treating passengers as though inviting friends to the living room. This logic of calling up emotional memories to offer personal hospitality is vastly adapted among service industry practitioners. It can result in a sincere smile that is a displayed asset of a company. However, when workers practice such logic for years, this smiling is separated from its original function, which is expressing a personal feeling and is attached to another kind of single-expression public emotion of the company. This can create guilty feelings or thoughts in some practitioners: "Am I phony?" They can experience burnout in their jobs due to the "battle of smiles." Some companies provide recurring training for experienced or senior staff, which aims to prevent burnout (Brotheridge and Grandey, 2002) regarding emotional service from turning into anger toward the job. This work stress loop is common among hospitality practitioners (Ross, 1995).

\subsection{Service quality}

Many researchers and scholars have contributed to an understanding of service quality in the hospitality industry. The prominent conceptual framework has been found divergent (Prakash and Mohanty, 2013). Parasuraman et al. (1988) first introduced SERVQUAL as a multi-item scale to assess service quality, which is defined as "the degree and direction of discrepancy between customers' service perceptions and expectations.” Prakash and Mohanty (2013) proposed the idea of a service blueprint. The key components are 
(1) customer actions, (2) onstage/visible contact employee actions, (3) backstage/invisible contact employee actions and (4) support processes and physical evidence. An important component that relates to this research is the backstage/invisible contact employee actions, distinguished from visible actions, which are "everything that appears above the line of visibility [and are] seen by the customer, while everything below it is invisible."

The literature provided a theoretical framework for investigating the effects of wearing face masks during the COVID-19 crisis. More understanding of the perceptions of managers, practitioners and customers would help the hospitality industry to better prepare for the ongoing crisis.

\section{Methodology}

\subsection{Research setting}

The face-to-face and focus group interviews were conducted with managers, practitioners and customers of hotels in Hong Kong. Hong Kong was chosen as the setting of the study because the city had widely adopted the wearing of face masks during the COVID-19 pandemic. This study used convenience sampling of 14 managers, 6 practitioners and 15 customers, for a total of 35 respondents, based on ease of access by the researchers. For both managers/practitioners and customers, the researchers developed the same set of seven open-ended questions to be posed in the interviews (see Appendix). The researchers also developed a questionnaire on demographic characteristics, including nationality, gender, age, hotel stars and job position (see Table 1). The two latter aspects were excluded for customers (see Table 2).

\subsection{Data collection and analysis}

The interviews were conducted in either English or Cantonese, depending on the preferences of the interviewees. The study employed the snowball sampling method. The first interview was conducted on June 16, 2020 and the final interview was conducted June 24, 2020.

\begin{tabular}{llllll}
\hline ID & Star rating & Job position & Nationality & Gender & Age \\
\hline H1 & 5 & Receptionist & Hong Kong & Female & $25-34$ \\
H2 & 5 & Manager & Hong Kong & Male & $45-54$ \\
H3 & 5 & Supervisor & Hong Kong & Male & $35-44$ \\
H4 & 5 & Food and beverage manager & Hong Kong & Male & $35-44$ \\
H5 & 5 & Waiter & Hong Kong & Male & $35-44$ \\
H6 & 3 & Assistant restaurant manager & Hong Kong & Male & $25-34$ \\
H7 & 5 & Housekeeper & Hong Kong & Male & $45-54$ \\
H8 & 4 & Front office manager & Hong Kong & Female & $35-44$ \\
H9 & 4 & Quality assurance & Hong Kong & Female & $25-34$ \\
H10 & 5 & Food and beverage manager & Hong Kong & Male & $35-44$ \\
H11 & 5 & Manager & Hong Kong & Male & $45-54$ \\
H12 & 4 & General manager & Singapore & Male & $45-54$ \\
H13 & 4 & Front office clerk & Hong Kong & Female & $25-34$ \\
H14 & 3 & Manager & Hong Kong & Male & $35-44$ \\
H15 & 4 & Front office manager & Hong Kong & Male & $45-54$ \\
H16 & 4 & Restaurant manager & Hong Kong & Male & $45-54$ \\
H17 & 5 & Director of business development & China & Male & $45-54$ \\
H18 & 4 & Operations manager & China & Male & $25-34$ \\
H19 & 4 & Operations manager & China & Male & $25-34$ \\
H20 & 4 & Chief operating officer & Canada of respondents & Male & 55-64 \\
& & & & & (managers and \\
\end{tabular}

Face masks effects in the hotel industry 


\begin{tabular}{llllr} 
IHR & & Nationality & Gender & Age \\
\cline { 2 - 5 } 35,2 & ID & Hong Kong & Male & $25-34$ \\
& C1 & Canada & Male & $35-44$ \\
& C2 & Hong Kong & Male & $45-54$ \\
& C3 & Hong Kong & Male & $45-54$ \\
& C4 & Hong Kong & Male & $35-44$ \\
$\mathbf{2 0 0}$ & C5 & England & Male & $18-24$ \\
& C6 & Hong Kong & Male & $55-64$ \\
& C7 & Hong Kong & Male & $35-44$ \\
& C8 & Hong Kong & Female & Male \\
& C1 & Hong Kong & Female & $45-54$ \\
& C10 & Hong Kong & Male & $18-24$ \\
Table 2. & C11 & Hong Kong & Female & $45-54$ \\
Profile of respondents \\
(customers)
\end{tabular}

Interviews took between 30 and 60 minutes. The ideal sample size for a qualitative study is between 15 and 40 participants (Köseoglu et al., 2020) if the data are sufficiently saturated. The interview for managers and practitioners was saturated with 20 respondents in Table 1 ( 5 additional interviews were conducted) and the interview for customers was saturated with 15 respondents in Table 2.

A bilingual (English and Cantonese) researcher transcribed the interviews. The interviews were recorded in English for further coding purposes. The data were manually analyzed for this exploratory study, although there are a lot of computing tools for qualitative analysis. This choice provides an advantage for an interpretative approach rather than just doing a mechanical analysis using software (Gröschl, 2005). For the data analysis, the researchers recorded all the answers from interviewees for each question and put them into a table format (see Table 3) in order to identify and quantify the similarities and differences.

\section{Results and findings}

Table 3 summarizes the opinions of managers/practitioners and customers on wearing face masks during the COVID-19 pandemic.

There are 7 thematic findings in the study:

T1. Hygiene and safety: It was generally agreed that the main purpose of wearing face masks is for hygiene and safety to protect both practitioners and customers. Hygiene and safety are the main concerns.

T2. Feelings on wearing face masks: Most respondents felt normal and fine. Some practitioners were suffering from allergies, feeling uncomfortable and breathing difficulties due to the quality of their face masks. A few customers felt that it was necessary to speak loudly, and that it was difficult to communicate without seeing facial expressions.

T3. Feelings on not wearing face masks: There was a marked contrast between practitioners and customers. Although practitioners felt unsafe and unprotected, they empathetically accepted that customers may feel uncomfortable and/or might have forgotten. In contrast, customers felt that this was unpleasant and unsafe and reacted with feelings of disgust, anger and fear related to spreading infections. 


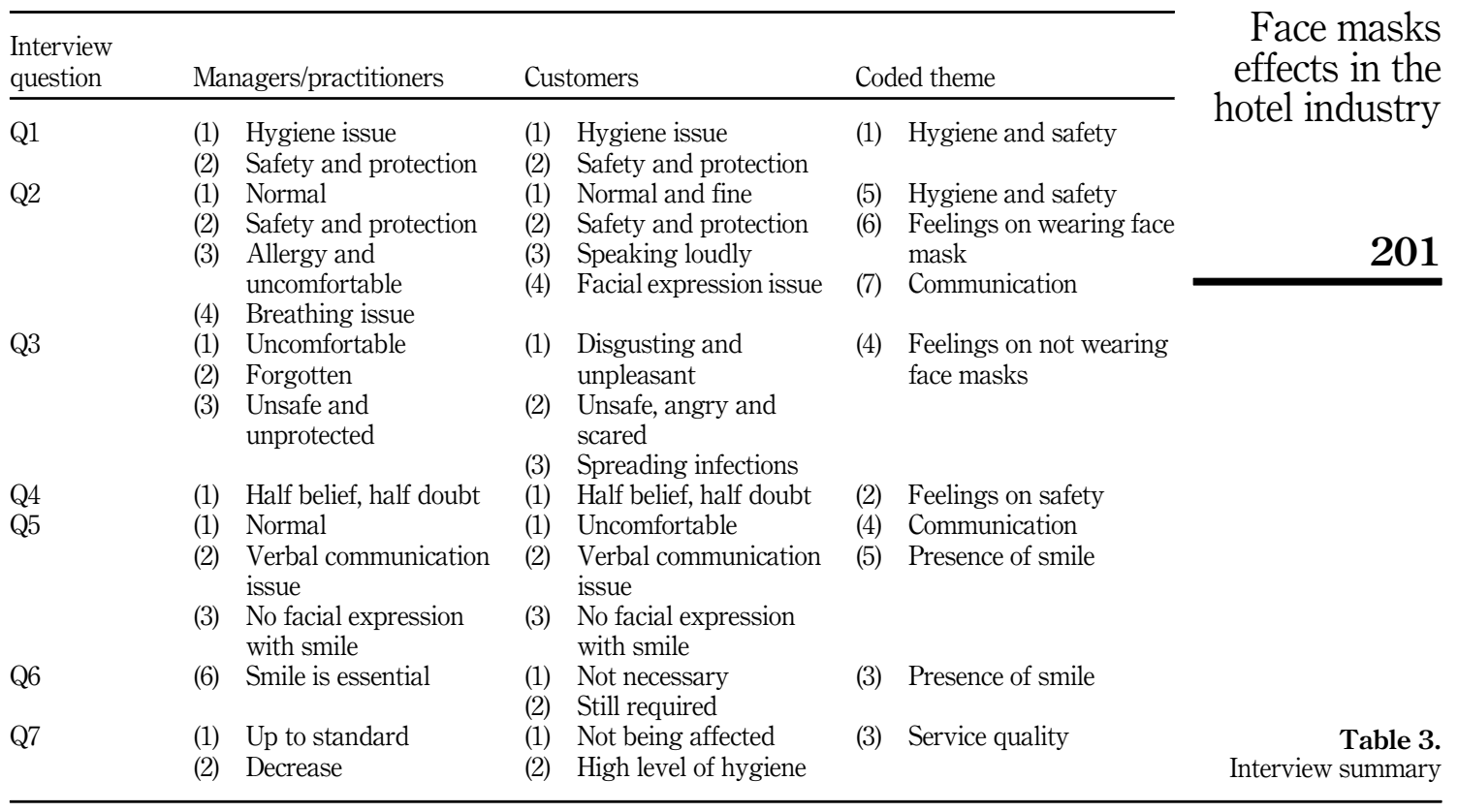

T4. Feelings on safety: The respondents half believed and half doubted that face masks could protect them from COVID-19 but still chose to use them.

T5. Communication: It was generally agreed that wearing face masks would affect the ease of verbal communication.

T6. Presence of smile: There was a marked contrast between practitioners and customers. Practitioners thought that smiles were essential; however, customers felt that they were not necessary and only optional.

T7. Service quality: Practitioners had a slightly negative impression regarding service quality, while customers felt that it was not affected. Customers appreciated the higher level of hygiene and were satisfied with the service quality.

\section{Discussions}

\subsection{Invisible care}

A new form of caring emerged during the COVID-19 pandemic: face masking wearing is a symbol of care and trust for both practitioners and customers. Face masks make intangible hygiene and safety tangible, representing a form of invisible care in Asian hospitality. It is found that the presence of a smile is not necessary for Asian customers, but it can still create a sense of caring and a good mood. Respondent C3 mentioned that "eye contact and speaking tone are more important than a smile," and respondent C13 pointed out that it is "stupid, no one cares about your smile during the COVID-19 pandemic."

\subsection{Sense of safety}

Customers are extremely concerned about their sense of safety. Although they understand that wearing face masks is a safety precaution without any proven scientific evidence, there is 
IHR

35,2

\section{2}

Figure 1.

The conceptual model of face mask effects a high expectation that service providers wear face masks. It is therefore an essential practice for all hospitality practitioners. Wearing face masks when providing service gives customers a sense of safety. It also works vice versa for the practitioners. They have been exposed to the virus by hotel guests who go under quarantine. The sense of safety has become the gesture, quality service and sign of caring by both hotel personnel and customers.

\subsection{Service trust}

The study shows that hygiene and service quality have decreased. Respondent H7 said, "we cannot guarantee that the room is completely clean during the pandemic, especially considering the customers who checked in for quarantine." However, customers have high confidence in hotel services and believe that they are maintaining a higher level of hygiene than before.

The study, therefore, reveals that the perceptions and expectations of practitioners and customers in hotel services differ.

\subsection{Conceptual model}

The study has revealed 3 major components of face make effects from managers, practitioners and customers during the COVID-19 pandemic. It can be illustrated into a conceptual model of face mask effects (Figure 1), namely, 1. invisible care, 2. sense of safety and 3. service trust.

From the findings of the study, the conceptual relationship (Figure 2) has been proposed. The gesture of wearing face mask in service may contain a correlation between invisible care, sense of safety and service trust in view of both the practitioner and customer in service during the COVID-19 pandemic. Service trust may also correlate by both invisible care and sense of safety.

In response to the research questions raised from the study.

(1) What are the effects generated by wearing surgical face masks? The action of wearing surgical face masks on hospitality practitioners has generated an invisible care and a sense of safety feeling in customers. Eventually, it builds a service trust between practitioners and customers.

(2) How do hospitality practitioners serve customers while wearing surgical face masks? Wearing face mask has little barrier to be overcome than actual safety and protection. The smile, face expression and verbal communication issue is still there, but it is not difficult to solve.

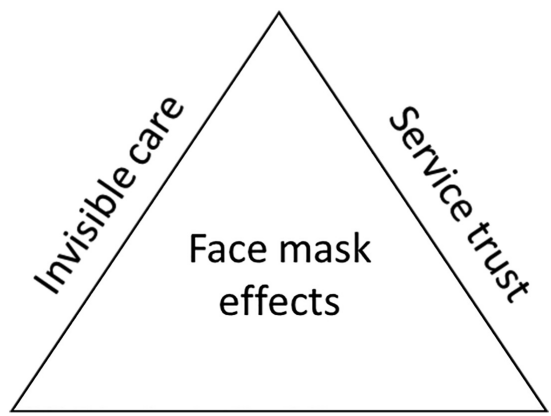

Sense of safety 


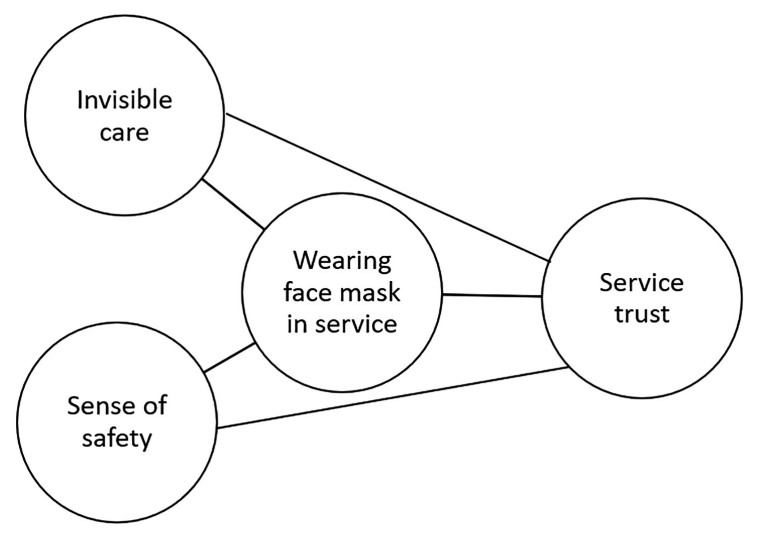

Face masks effects in the hotel industry

(3) Does wearing a mask affect the perceived experience of customers? Not very much experience has been affected, but it may increase the perceived quality of service experience with face mask effects.

\section{Conclusion, limitations and further study}

The hospitality industry has dynamically and drastically changed during the COVID-19 pandemic. The uncertainty around the future travel landscape has forced businesses to come up with new business models with stronger hygiene practices, newer or more flexible communication skills and a new perspective of caring for their guests. Therefore, there is a strong demand for scholarly works focusing on new and quickly adapted industry practices. This study supports future research that will help to improve service design to tackle largescale health crises. It also contributes to the understanding of the perceptions of practitioners and customers in the hospitality industry during the COVID-19 pandemic.

In this study, we analyzed interview data collected from 35 respondents -14 managers, 6 practitioners and 15 customers - in order to understand the critical effects of wearing face masks during the pandemic and the perspectives of both hospitality practitioners and customers. Our findings show that wearing face masks turns hygiene and safety into a form of invisible care in the Asian hospitality industry. Practitioners' perspective regarding the necessity of a smile is less important to Asian customers, showing a discrepancy between the two parties. Customers also do not believe that service quality has dropped due to the wearing of masks, but that the level of hygiene has risen. Unlike customers, practitioners are more concerned about not providing good quality service. However, the interview data show that respondents generally agree that mask wearing is a gesture and symbol for the hospitality industry to make tangible a new form of caring, professionalism, safety concern and communication.

While this study does not cover the general circumstances of the industry during the COVID-19 pandemic, in-depth and focus group interviews with managers, practitioners and customers could provide insightful context and possibly suggest a new model for the success of the future hospitality industry. The study has limitations as it grounds a new approach and theory in the challenging time of COVID-19, and the most appropriate data collection method was in-depth interviews. The conceptual models introduced in this study could be further investigated. Future studies should aim to verify the findings and should expand the range of demographics of the respondents, possibly to cover a bigger region. A worthwhile endeavor 
IHR

35,2

would be a comparative study to explain cultural or geographical differences in terms of preparation for the unforeseen crisis.

\section{References}

Brotheridge, C. and Grandey, A. (2002), "Emotional labor and burnout: comparing two perspectives of 'people work", Journal of Vocational Behavior, Vol. 60 No. 1, pp. 17-39.

Brownell, J. (1992), "Hospitality managers' communication practices", International Journal of Hospitality Management, Vol. 11 No. 2, pp. 111-128.

Centre for Health Protection (2020a), Guidelines on Prevention of Coronavirus Disease 2019 (COVID-19) for the General Public, Hong Kong Department of Health, available at: https://www. chp.gov.hk/files/pdf/nid_guideline_general_public_en.pdf.

Centre for Health Protection (2020b), Health Advice on Prevention of Coronavirus Disease (COVID-19) for Hotel Industry, Hong Kong Department of Health, available at: https://www.chp.gov.hk/files/ pdf/nid_guideline_hotel_serving_guests_eng.pdf.

Chien, G.C.L. and Law, R. (2003), "The impact of the Severe Acute Respiratory Syndrome on hotels: a case study of Hong Kong", International Journal of Hospitality Management, Vol. 22 No. 3, pp. 327-332.

Chu, K.H.-L. and Murrmann, S.K. (2006), "Development and validation of the hospitality emotional labor scale", Tourism Management, Vol. 27 No. 6, pp. 1181-1191.

Dimberg, U., Thunberg, M. and Elmehed, K. (2000), "Unconscious facial reactions to emotional facial expressions", Psychological Science, Vol. 11 No. 1, pp. 86-89.

Feng, S., Shen, C., Xia, N., Song, W., Fan, M. and Cowling, B.J. (2020), "Rational use of face masks in the COVID-19 pandemic", The Lancet Respiratory Medicine, Vol. 8 No. 5, pp. 434-436.

Gossling, S., Scott, D. and Hall, M. (2020), "Pandemics, tourism and global change: a rapid assessment of COVID-19", Journal of Sustainable Tourism. doi: 10.1080/09669582.2020.1758708.

Gröschl, S. (2005), "Persons with disabilities: a source of nontraditional labor for Canada's hotel industry”, Cornell Hotel and Restaurant Administration Quarterly, Vol. 46 No. 2, pp. 258-274.

Hong Kong Business (2020), Hotels make Further Room Rate Cuts to Survive, available at: https:// hongkongbusiness.hk/hotels-tourism/in-focus/hotels-make-further-room-rate-cuts-survive-0.

Hong Kong Tourism Board (2020), Research \& Statistics, available at: https://partnernet.hktb.com/en/ research_statistics/index.html (accessed 10 June 2020).

Hung, K.K.C., Mark, C.K.M., Yeung, M.P.S., Chan, E.Y.Y. and Graham, C.A. (2018), "The role of the hotel industry in the response to emerging epidemics: a case study of SARS in 2003 and H1N1 swine flu in 2009 in Hong Kong", Globalization and Health, Vol. 14 No. 1, p. 117.

Islam, M. and Kirillova, K. (2020), "Non-verbal communication in hospitality: at the intersection of religion and gender", International Journal of Hospitality Management, Vol. 84 No. 2020, doi: 10.1016/j.ijhm.2019.102326.

Jones, P. and Comfort, D. (2020), "The COVID-19 crisis, tourism and sustainable development", Athens Journal of Tourism, Vol. 7 No. 2, pp. 75-86.

Jung, H.S. and Yoon, H.H. (2011), "The effects of nonverbal communication of employees in the family restaurant upon customers' emotional responses and customer satisfaction", International Journal of Hospitality Management, Vol. 30 No. 3, pp. 542-550.

Kim, S.S., Chun, H. and Lee, H. (2005), "The effects of SARS on the Korean hotel industry and measures to overcome the crisis: a case study of six Korean five-star hotels", Asia Pacific Journal of Tourism Research, Vol. 10 No. 4, pp. 369-377.

Knapp, M. and Hall, J. (2010), Nonverbal Communication in Human Interaction, 7th ed., Wadsworth, Boston, MA.

Köseoglu, M.A., Altin, M., Chan, E. and Aladge, O.F. (2020), "What are the key success factors for strategy formulation and implementation? Perspectives of managers in the hotel industry", 
International Journal of Hospitality Management, Vol. 89, 102574, doi: 10.1016/j.ijhm.2020. 102574.

Kueh, S. and Bagul, A.H.B.P. (2013), "The effects of nonverbal communication of hotel employees upon emotional responses of hotel guests", International Journal of Reseach in Management and Technology, Vol. 3 No. 4, pp. 126-135.

Lau, S. (2020), Coronavirus: World Health Organisation Reverses Course, Now Supports Wearing Face Masks in Public, South China Morning Post, available at: https://www.scmp.com/news/china/ article/3078407/coronavirus-world-health-organisation-reverses-course-now-supports.

Lee, D. (2020), Coronavirus: Lockdowns Are Not the Reason Hong Kong and South Korea Are Beating COVID-19. Model Citizens Might Be, South China Morning Post, available at: https://www. scmp.com/week-asia/health-environment/article/3080764/coronavirus-lockdowns-are-notreason-hong-kong-and.

Lemon, K.N. and Verhoef, P.C. (2016), "Understanding customer experience throughout the customer journey”, Journal of Marketing, Vol. 80 No. 6, pp. 69-96.

Nikolich, M.A. and Sparks, B.A. (1995), "The hospitality service encounter: the role of communication", Hospitality Research Journal, Vol. 19 No. 2, pp. 43-56, doi: 10.1177/109634809501900205.

Parasuraman, A., Zeithaml, V.A. and Berry, L.L. (1988), "SERVQUAL: a multiple-item scale for measuring consumer perceptions of service quality", Journal of Retailing, Vol. 64 No. 1, pp. $12-40$.

Prakash, A. and Mohanty, R.P. (2013), "Understanding service quality", Production Planning and Control, Vol. 24 No. 12, pp. 1050-1065, doi: 10.1080/09537287.2011.643929.

Radio Television Hong Kong (2020), Hotel Staff At Risk from Quarantined Guests, available at: https:// news.rthk.hk/rthk/en/component/k2/1518623-20200403.htm.

Ross, G. (1995), “Work stress and personality measures among hospitality industry employees", International Journal of Contemporary Hospitality Management, Vol. 7 No. 6, pp. 9-13.

Severson, K. (2020), "The new face of restaurant hospitality wears a mask", New York Times, available at: https://www.nytimes.com/2020/05/18/dining/restaurants-masks-coronavirus.html.

Sperber, D. and Wilson, D. (1995), Relevance: Communication and Cognition, 2nd ed., Blackwell Publishing, Oxford.

Spelman, D.H. (1985), "The managed heart: commercialization of human feeling”, The Academy of Management Review, Vol. 10 No. 2, pp. 375-377.

Taheri, B., Coelho, F., Sousa, C. and Evanschitzky, H. (2017), "Mood regulation, customer participation, and customer value creation in hospitality services", International Journal of Contemporary Hospitality Management, Vol. 29 No. 12, pp. 3063-3081.

Tang, R. and Wong, A. (2020), "Unprecedented times to explore hotel opportunities", Colliers International, available at: https://www2.colliers.com/en-HK/Research/Colliers-FlashUnprecedented-times-to-explore-hotel-opportunities.

Tse, Tony, S.M. and Prideaux, B. (2017), "Tourism planning requirements from a private sector perspective: the case of Hong Kong", Current Issues in Tourism, Vol. 20 No. 12, pp. 1210-1214, doi: 10.1080/13683500.2016.1265489.

Tucker, E., Qu, H., Fang, X., Njite, D. and Ryan, B. (2011), An Experimental and Causal Study of the Effects of Training on Service Employees' Emotional Labor and Well-Being, Ph.D. Thesis, Oklahoma State University, Stillwater, Oklahoma, ProQuest Dissertations \& Theses Global.

Wessel, J.L. and Steiner, D.D. (2014), "Surface acting in service: a two-context examination of customer power and politeness", Human Relations, Vol. 68 No. 5, pp. 709-730.

World Health Organization (WHO) (2020), WHO Director-General's Opening Remarks At The Media Briefing on COVID-19-11 March 2020, available at: https://www.who.int/dg/speeches/detail/ who-director-general-s-opening-remarks-at-the-media-briefing-on-COVID-19-11-march-2020.
Face masks effects in the hotel industry 
IHR

35,2

\section{6}

Zeithaml, V.A., Berry, L.L. and Parasuraman, A. (1996), "The behavioral consequences of service quality", The Journal of Marketing, Vol. 60 No. 2, pp. 31-46.

Zheng, S. (2020), Face Masks and Coronavirus: How Culture Affects Your Decision to Wear One, South China Morning Post, available at: https:/www.scmp.com/news/china/society/article/3075211/ face-masks-and-coronavirus-how-culture-affects-your-decision.

\title{
Appendix
}

\section{Interview questions}

Managers/practitioners:

Q1. What factors do you consider when you are wearing a face mask?

Q2. How do you feel when you are wearing a face mask while providing service?

Q3. How do you feel or what do you think when the customer is not wearing a face mask?

Q4. Do you believe that wearing a face mask is successful or effective in protecting you?

Q5. What challenges related to providing service do you experience when you are wearing a face mask?

Q6. Do you believe that a smile is important in the hospitality industry during the pandemic?

Q7. How would you describe the service quality during the pandemic?

\section{Customers:}

Q1. What factors do you consider when you are wearing a face mask?

Q2. How do you feel when you are wearing a face mask while being served?

Q3. How do you feel or what do you think when the person serving you is not wearing a face mask?

Q4. Do you believe that wearing a face mask is successful or effective in protecting you?

Q5. What challenges related to receiving service do you experience when you are wearing a face mask?

Q6. Do you believe that a smile is important in the hospitality industry during the pandemic?

Q7. How would you describe the service quality during the pandemic?

\begin{abstract}
About the authors
Anthony Kong is an Assistant Professor in Digital Media in the School of Design at The Hong Kong Polytechnic University. He is an academician and professional with profound knowledge and expertise in an interdisciplinary area of design, technology and hospitality. He holds a bachelor's degree in computing at the University of Portsmouth, a master's degree in design and a doctoral degree in hotel and tourism management at The Hong Kong Polytechnic University. He is currently serving as an executive committee member for both the Hong Kong Designers Association and IEEE Hong Kong Section Computer Society Chapter. His research interests lie in the interdisciplinary area of digital media, educational technology, service design and smart design. Anthony Kong is the corresponding author and can be contacted at: anthony-pui-keung.kong@polyu.edu.hk

Jae-Eun Oh has been teaching in higher education for the last 15 years and has built her research path on the animation narrative that has focused on semiotics and the psychological effect for the theme park industry. Besides animation storytelling, she is into design education for the media students' motivation in the studio/project-based learning where they learn to create their media artifacts.

Terry, Wai-Man Lam has been teaching in the Hong Kong Polytechnic University and other higher education institutes for 6 years. He has 20 years of experience in the media creative practice and is now a
\end{abstract}


Ph.D. candidate at RMIT University at the School of Design and Social Context. He is building his research path on creative practice that focuses on action narrative and creative practice development. He also participates in immersive media and interaction for creative practice research projects during the time in the meaningful game research center at the School of Design at the Hong Kong Polytechnic University.
Face masks effects in the hotel industry

For instructions on how to order reprints of this article, please visit our website: www.emeraldgrouppublishing.com/licensing/reprints.htm Or contact us for further details: permissions@emeraldinsight.com 